\title{
A inédita participação do Brasil na MINUSTAH e os desafios de uma solução duradoura para o Haiti
}

The unprecedented participation of Brazil in MINUSTAH and the challenges of a lasting solution to Haiti

Guilherme Athaides Guimarães ${ }^{1}$

\begin{abstract}
RESUMO
O artigo em questão está dividido em três partes. Primeiramente, busca-se resgatar a história do Haiti. Depois, apresenta-se o histórico das missões da ONU para o Haiti e porque a participação do Brasil na MINUSTAH se revestiu de um caráter inédito. Na terceira parte, sustenta-se que a fonte dos problemas do Haiti é política e que a superação deles passa pelo empoderamento do povo haitiano, através, sobretudo, da educação e da conscientização política, uma vez que ele é o principal ator no desenvolvimento do país.
\end{abstract}

Palavras-chave: Haiti; Brasil; MINUSTAH.

\begin{abstract}
The article in question is divided into three parts. First, it seeks to rescue the history of Haiti. Then, it presents the history of UN missions to Haiti and why Brazil's participation in MINUSTAH was clothed in an unprecedented character. In the third part, it argues that the source of Haiti's problems is political and that overcoming them requires the empowerment of the Haitian folk, through, above all, education and political awareness, inasmuch as it is the main actor in the country's development.
\end{abstract}

Key-words: Haiti; Brazil, MINUSTAH.

\section{INTRODUÇÃO}

Primeiro país a conquistar a Independência na América Latina, o Haiti tem vivido uma história marcada pela instabilidade política, econômica e social. Constantes rupturas políticas impediram o desenvolvimento de uma ação continua e organizada voltada para o desenvolvimento do país. Segundo estudos do National Republican Institute for International Affairs (1991), foi só em 1990 que houve as primeiras eleições comprometidas em conduzir ao poder um governo democraticamente eleito a um país que nunca antes em sua história teve um. 0 primeiro presidente do país eleito de forma

\footnotetext{
1 Graduando do curso de Direito da Universidade Federal do Paraná (UFPR), Curitiba, Brasil. Faz parte do projeto Migrações, Refúgio e Hospitalidade da UFPR, do PET-Direito e é bolsista voluntário de Iniciação Científica.
} 
democrática, porém, seria rapidamente deposto por um golpe de estado. A comunidade internacional reagiu a isto por meio de um embargo comercial, aprovado pelo CSONU. Mas logo se percebeu que este tipo de medida seria ineficiente. Lançou-se então, em setembro de 1993, por meio da Resolução 867 do CSONU, a primeira Missão das Nações Unidas para o Haiti (UNMIH) (http://www.un.org).

Mais de 20 anos se passaram desde a primeira missão da ONU para o Haiti. Em 2004, foi lançada a quarta missão da ONU para o país, a Missão de Estabilização das Nações Unidas no Haiti (MINUSTAH), cujo comando o Brasil ineditamente assumiu. Mais que uma resposta temporária para a crise que o país enfrenta, a MINUSTAH deve levar em consideração as condições históricas que conformaram o Haiti. A superação de grande parte dos seus problemas, como a história tem revelado, passa necessariamente pelo empoderamento do povo haitiano, o que compreende, sobretudo, o fomento à educação e a conscientização político-social. É preciso que a reconstrução do Haiti vá além dos aspectos materiais e políticos mais superficiais. A atuação da comunidade internacional é passageira, mas a do povo haitiano é permanente.

\section{De Pérola das Antilhas a vale de instabilidade}

As Antilhas, região da América Central, com seus produtos tropicais, como melado, açúcar, rum e cacau, foram o epicentro do comércio mundial e da disputa por hegemonia entre o século XVII e XIX. A “Pérola das Antilhas”, futuro Haiti, foi cedido pela Espanha à França em 1697, por meio Tratado de Rijswijk, sob a insígnia de St. Domingo Francês (FERGUNSON, 2015).

A parte da ilha pertencentes à França se conformou com uma estrutura social própria. Havia os escravos, os gens de couleur (negros livres) e os grands blancs (colonos brancos abastados), e mais algumas classes intermediárias. Os gens de couleur, ao longo do século XVIII, prosperaram e passaram a competir com os grands blancs, adquirindo terras e assimilando o estilo de vida destes. Para se ter noção da importância dos gens de couleur, estima-se que, em 1791, um terço das terras e um quarto dos escravos pertenciam a eles (MINTZ, 1995). 
Os gens de couleur, no entanto, não foram a principal força da Revolução que estourou em 1791, como os criollos o foram para a Independência do resto da América Latina. Foram os escravos. Não obstante, depois da vitória haitiana, proclamada em 1o de janeiro de 1804 por Jean Jacques Dessalines, os gens de couleur que se engajaram no conflito passaram a ocupar posições de destaque ao lado dos líderes da Revolução, centralizando o poder político (MINTZ, 2005). Segundo Matijascic (2010), após a Independência o "poder manteve-se centralizado na minoria mulata, garantindo privilégios e defesa de interesses para esta elite com o trabalho da grande parcela dos haitianos, os ex-escravos negros".

O manto vermelho vivo que foi estendido para se alcançar sublime triunfo não garantiu a prosperidade da jovem nação. O Haiti estava cercado por colônias escravocratas, subordinadas a potências coloniais hostis, temerosas de que revoluções semelhantes desbaratassem pelo continente. 0 país, que teve sua economia devastada durante a guerra, foi ostracisado diplomaticamente e comercialmente, mergulhando em um período de inconsistência política (FERGUSON, 2015).

A instabilidade marcou sua história. 0 país conheceu dezenas de golpes de Estado e até algumas más sucedidas tentativas de se estabelecer um reino:

\begin{abstract}
Da independência, em 1804, até 2004, ano da queda do Presidente JeanBertrand Aristide, o Haiti teve 41 governantes. Desse total, um suicidou-se, o segundo rei do país recém-independente, Henri Christophe; 28 foram destituídos ou levados a renunciar, por força de golpes de Estado ou pressões da oposição; 4 foram assassinados; 3 outros, o general Alexandre Pétion, em 1818, Jean-Baptiste Riché, em 1847 e François Duvalier, em 1971, tiveram morte natural durante o exercício de mandatos vitalícios e 3 durante o cumprimento de mandatos não-vitalícios Philippe Guerrier, em 1845, Florvil Hyppolite, em 1896 e Tancrède Auguste, em 1913. Em dois séculos como Estado independente, só Ertha Pascal-Trouillot chegaria ao final de um mandato constitucional. A partir de 1991, com a eleição de Jean-Bertrand Aristide, diversos golpes e contra-golpes se sucederiam e dariam origem a crises que levariam a diversas intervenções internacionais (VALLER FILHO, 2007, p. 16).
\end{abstract}

As sublevações, porém, ficaram restritas à capital durante a maioria do século XIX. O interior do país permaneceu relativamente estável, praticando uma agricultura de subsistência e afastado da vida política. Quando os EUA ocuparam o Haiti, de 1915 a 1934, alguns problemas do país foram minorados, outros agravados. Por um lado, o país 
conheceu uma melhora na sua infraestrutura; por outro lado, a modernização do exército e a centralização do governo haitianos acabaram por contribuir para a manutenção do sistema tradicional de poder, concentrado e restrito à elite (MINTZ, 2015).

A intervenção norte-americana abriu as portas para que mais intervenções ocorressem. As elites locais, cada vez mais fortalecidas, viram nas intervenções um meio de arregimentação política:

As interferências no Haiti aconteceram não só por desrespeito à soberania do país, mas também pelas ligações das elites locais que, quando ameaçadas pela pressão popular por reformas, recorriam ao auxílio da interferência externa para manterem o status quo (SANTOS CRUZ, 2010).

Em 1957, o país experimentou sua primeira eleição por sufrágio universal. Na ocasião, François Duvalier, mais conhecido como "Papa Doc", foi eleito Presidente. Não demorou para que ele iniciasse uma bruta repressão à oposição e se declarasse, em 1964, "Prèsident à vie". Papa Doc faleceu em 1971, mas antes transferiu seu "título" de "Presidente eterno" para seu filho de 19 anos, Jean-Claude Duvalier, mais conhecido como Baby Doc. Este permaneceu 15 anos no poder (1971-1986), até que a crescente oposição popular forçou-o a se exilar na França. Instalou-se um Conselho Nacional de Governo provisório que ditou as ordens até a eleição de Jean-Bertrand Aristide, em 1991 (www.haitisupportgroup.org).

Em 1991, os EUA, por intermédio da CIA, patrocinaram um golpe de Estado no Haiti que derrubou, sequestrou e deportou o então presidente, eleito democraticamente, Jean-Bertrand Aristide. 0 país mergulhou novamente em uma ditadura, que durou até 1994. Neste ano, os Estados Unidos realizaram outra intervenção, baseada mais em interesses políticos e comerciais que humanitários. 0 Haiti, ao longo dos anos, até 2004, adotou programas de reforma econômica, ditadas pelos parâmetros do Consenso de Washington e do FMI, que acabaram por desestruturar a agricultura do país (CHOSSUDOVSKY, 2004).

O Haiti entrou no século XXI de forma crítica. A taxa de alfabetização do país é inferior a 50\%. Cerca de metade da população reside nas cidades. A outra parte, que fica no interior, está completamente alijada do processo político (CIA, 2014). Em 2004, foi 
lançada a quarta missão da ONU para o país, a Missão de Estabilização das Nações Unidas no Haiti (MINUSTAH), que se prolonga por mais de uma década. Não obstante, o país continua enfrentando instabilidade política e econômica e permanece como uma das nações mais pobres do mundo, situação agravada pelo terremoto de 2010.

\section{A inédita participação do Brasil na MINUSTAH}

Os laços entre o Brasil e o Haiti são recentes. Do século XIX, só fica registrado nos livros de história o medo das elites da "haitinização" do Brasil, Império escravista (ROCHA, 2000, p. 59). O Brasil votou pelo ostracismo do Haiti. As relações diplomáticas foram estabelecidas em 1928. Em 1966, os dois países assinaram um Convênio de Intercâmbio Cultural, e, em 1986, o ministro das Relações Exteriores do Haiti, Jean Robert Estimé, visitou o Brasil. Depois disso, veio a MINUSTAH, que deu início a uma nova fase das relações com o Haiti (http://www.itamaraty.gov.br/).

Em 30 de abril de 2004, a MINUSTAH foi criada pela Resolução de 1.542 do Conselho de Segurança das Nações Unidas, substituindo a Força Multinacional Interina, criada pela Resolução 1.529. A quarta Operação de Paz da ONU para o Haiti², no entanto, contou com um elemento inédito: 0 Brasil, que nunca tinha participado de uma operação de paz no Haiti, assumiria o comando da missão (VALLER FILHO, 2007, pp. 16, 17).

Desde que Bouthros Bouthros-Ghali, em 1992, lançou a Agenda para a Paz diferindo Operações de Manutenção de Paz (Peacekeeping Operations) de Operações de Imposição de Paz (Peacemaking Operations), o Brasil tem sido cauteloso em relação a estas. Embora o projeto do Secretário Geral não tenha sido adotado, justamente por resistência de Estados, dentre eles o Brasil, preocupados com que Operações de Imposição de Paz fossem meios das potências interferirem em assuntos internos de outros Estados, o termo ficou consagrado. Adotou-se o entendimento de que as Operações de Manutenção de Paz seriam aquelas baseadas no capítulo VI da Carta da

\footnotetext{
2 As missões anteriores foram: United Nations Mission in Haiti (UNMIH), de 9/1993 a 6/1996; United Nations Support Mission in Haiti (UNSMIH), de 7/1996 a 7/1997; United Nations Transition Mission in Haiti (UNTMIH), de 8/1997 a 11/1997.
} 
ONU, e as Operações de Imposição de Paz aquelas baseadas no capítulo VII (DINIZ, 2006, p. 319-320).

O Brasil tem apresentado uma postura arredia em relação às Operações de Paz, "acting under chapter VII", e esta é a razão pela qual o país não participou das missões de paz que ocorreram anteriormente no Haiti, uma vez que nelas invocava-se o Capítulo VII. Embora a Resolução 1.542 também o invoque, ela o faz apenas no $§ 7^{\circ}$ ‥ Assim, o governo brasileiro afirma que a Resolução não se baseia totalmente no capítulo VII, o que lhe permite participar da missão sem abandonar seus princípios, sobretudo o da não-intervenção (REZENDE, 2012). Não obstante, nas Resoluções ${ }^{3}$ seguintes referentes à MINUSTAH, o CSONU, sem exceção, afirmou estar agindo com base no Capítulo VII da Carta da ONU (http://www.un.org/).

Embora esteja previsto no art. 4º , IV, da Constituição que o Brasil será regido em suas relações internacionais pelo princípio da não-intervenção, a intervenção no Haiti é consentida. Como assevera Seintenfus (2006, p. 15) o "Haiti é bom exemplo de intervenção requerida de modo insistente pelas autoridades depostas e recebida com entusiasmo e alívio pela população". Nesse sentido, a atuação no Haiti, no momento atual, não representa um desrespeito à soberania, pois o governo local, embora fragilizado, atua de forma coordenada com as forças internacionais.

Apesar da controvérsia acerca da natureza da missão, o Brasil assumiu sua liderança e vem trabalhando arduamente para cumprir o mandato da missão. Esta tem como seus pontos principais garantir a segurança, a estabilidade política e social, a reconstrução das instituições governamentais do país, o respeito ao Estado de direito e aos direitos humanos (http://www.un.org).

Interessante observar que o Brasil não possui os mesmos laços históricos e culturais com o Haiti que ele possui com as demais nações com as quais enceta uma cooperação ativa, como Timor-Leste e Guiné-Bissau. Sem dúvida, o Haiti é muito mais ligado aos EUA, que já efetuou no país diversas intervenções, ou à França, responsável pela colonização (LINS DA SILVA, 2004).

\footnotetext{
${ }^{3}$ Desde a Resolução n. 1.542 (2004), o CSONU aprovou mais seis Resoluções referentes à questão, quais sejam: 1.892 (2009); 1.927 (2010); 2.012 (2011); 2.070 (2012); 2.119 (2013); 2.180 (2014). 
A atuação do Brasil no Haiti é caracterizada tanto pela coordenação com os demais países latino-americanos, como por um perfil próprio. Após o terremoto, as ações do país passaram a estar mais relacionadas tanto com a expectativa do povo haitiano, como da comunidade internacional (HIRST, 2010).

\section{A necessidade de empoderamento do povo haitiano}

Após a crise que emergiu em 2010 no país, a insuficiência, inabilidade e vícios da ajuda e cooperação internacionais foram esquecidos, cedendo lugar a uma "enorme desconfiança da comunidade internacional quanto à capacidade e idoneidade das autoridades haitianas de gestionarem os recursos provenientes da cooperação internacional" (HIRST, 2010). No entanto, mais importante que se focar nas autoridades é se focar no povo haitiano. Uma elite política minoritária não muda um país. Muito mais importante é o papel que a totalidade dos indivíduos é capaz de representar, pois, como visto, o Haiti tem sido, em mais de dois séculos de Estado independente, governado através do revezamento, frequentemente violento, de elites políticas no poder.

A MINUSTAH provavelmente teria alcançado seu termo após as eleições presidenciais no país, em 2011. No entanto, o terremoto estremeceu esse otimista panorama. 0 país, que havia assumido a presidência da Caricom, recebido investimentos externos de diversos países da América Latina, entre eles Cuba, Brasil e México, e tinha passado por um fortalecimento institucional significativo, viu mais uma vez o seu destino nas mãos da comunidade internacional (HIRST, 2010).

Estima-se que o saldo da crise humanitária pós-catástrofe passou de $200 \mathrm{mil}$ mortos e 1,5 milhões de desabrigados (http://www.economist.com/). O Brasil reagiu energicamente aos novos desafios, assumindo o compromisso de aumentar a ajuda financeira e militar e estendendo sua ação à área da saúde, educacional, alimentar e de infraestrutura (HIRST, 2010). Não obstante, em cinco anos após a catástrofe, o país está muito pouco melhor do que estava antes do ocorrido, e em muitos campos está pior. Se, por um lado, a MINUSTAH, desde seu início, conseguiu reduzir a pobreza extrema, aumentar o número de indivíduos nas escolas e reduzir as mortes oriundas do crime organizado, por outro, a economia do país não conheceu uma melhora significativa (http://www.economist.com/). 
O foco em necessidades humanitárias imediatas do país é uma preocupação que norteia a ação dos doadores internacionais, mas a fonte das discórdias do país é política. Como se pode observar, a instabilidade política marcou sua história e muitos dos problemas por ele enfrentados derivam da ausência de um governo inclusivo, representativo e capaz de lidar com os problemas do país e, sobretudo, identificar mais os interesses nacionais que os seus particulares.

No Haiti, "a violência e o conflito têm suas origens na política, mas também têm raízes econômicas e continuam crescendo devido à ausência da autoridade estatal e à falta de desenvolvimento econômico e social" (ESCOTO, 2006, p. 89). Assim, a ajuda internacional deve ter como principal eixo a reconstrução da unidade e estabilidade política, seguido pelo saneamento de problemas econômicos e sociais. É necessário dar ao país autonomia e condições para que possa escrever os versos do seu futuro:

\footnotetext{
A solução dos problemas do Haiti passa por uma valorização e atribuição de responsabilidade total para o governo e para o povo haitiano que, apesar de sofrido, é notadamente capaz e criativo, e absolutamente credenciado para resolver seus próprios problemas (SANTOS CRUZ, 2010).
}

A ajuda internacional tem que ser transitória e voltada para o empoderamento de cada indivíduo nacional, ou seja, do povo haitiano como um todo. 0 empoderamento deve ser pessoal, grupal e estrutural:

O empoderamento pessoal possibilita a emancipação dos indivíduos, com aumento da autonomia e da liberdade. 0 nível grupal desencadeia respeito recíproco e apoio mútuo entre os membros do grupo, promovendo o sentimento de pertencimento, práticas solidárias e de reciprocidade. 0 empoderamento estrutural favorece e viabiliza o engajamento, a corresponsabilização e a participação social na perspectiva da cidadania (KLEBA; WENDAUSEN, 2009, p. 733).

A MINUSTAH, embora deva também se focar na superação imediata da crise humanitária pela qual o país passa, deve ter como objetivo de longo prazo o fortalecimento da educação no país. A própria Constituição Haitiana (1987), em seu art. $31^{\circ}$, §o $1^{\circ}$ já reconhece que "The first responsibility of the State and its territorial divisions is education of the masses, which is the only way the country can be developed." (HAITI, 1987). 
0 principal agente do desenvolvimento de um país é o seu próprio povo. No entanto, para que ele possa agir adequadamente, é imprescindível que haja, para além do seu empoderamento, o fortalecimento democrático nacional. A MINUSTAH tem a democratização dentre os seus objetivos (ESCOTO, 2009), mas é preciso ir além. Democratização não pode se resumir à reorganização do sistema político-eleitoral. John Locke (1994, p. 103) já apontava ser uma premissa básica da democracia o controle natural do poder comunitário por uma maioria. No Haiti, tem se verificado o contrário. Além disso, o fortalecimento democrático deve passar necessariamente pela garantia de condições propícias de diálogo, de participação política e de interação pública, três elementos que Amartya Sen (2009) aponta como centrais em uma democracia.

O Brasil deve dialogar com as autoridades locais em busca de identificar meios de emancipação social e econômica, em prol de obter uma solução duradoura para os problemas do país. É preciso trabalhar na construção de um consenso político nacional em que o principal agente seja o povo haitiano. Para isto, porém, fundamental é fomentar o desenvolvimento da educação no país, bem como a conscientização política da população.

\section{REFERÊNCIAS}

CHOSSUDOVSKY, M. The Destabilization of Haiti. Global Research, Ottawa, 29 Fevereiro 2004. Disponivel em: <http://globalresearch.ca/articles/CHO402D.html>. Acesso em: 8/02/2015.

CIA. The World Factbook: Central America and Caribbean: Haiti. 2013. Disponível em: <https://www.cia.gov/library/publications/download/>. Acesso em: 9/02/2015.

DINIZ, Eugenio. O Brasil e as Operações de Paz. p. 303-337. In: ALTEMANI, Henrique; LESSA, Antônio C. (Org). Relações Internacionais do Brasil: temas e agendas, v. II. São Paulo: Saraiva, 2006.

ESCOTO, Roberto. Construção do Estado e democratização do Haiti: uma análise das intervenções da ONU sob o enfoque da segurança humana (1993-1996 e 20042008). 2009. 134 f. Dissertação (Mestrado) - Curso de Relações Internacionais, Instituto de Relações Internacionais, Universidade de Brasília, Brasília, 2009. Disponível em: <http://bdtd.bce.unb.br/tedesimplificado/tde_busca/arquivo.php?codArquivo=5950>. Acesso em: 26/05/2015. 
FERGUSON, James A. "Haiti", 2015. In: Encyclopædia Britannica Online. Disponível em: http://www.britannica.com/EBchecked/topic/251961/Haiti>. Acesso em: 09 Fev. 2015.

HAITI. Constitution Of Haiti, 1987. Disponível em: $<$ http://pdba.georgetown.edu/Constitutions/Haiti/constitution1987en.pdf>. Acesso em: 26/05/2015.

HAITI Support Group. History of Haiti (1492 - 1986). Disponível em:<http://www.haitisupportgroup.org/index.php?option=com_content\&view=article \&id=345:history-1\&catid=98:history\&Itemid=218>. Acesso em: 8/02/2015.

HIRST, Monica. O Haiti e os desafios de uma reconstrução sustentável - um olhar sul-americano. Política Externa, v. 19, n. 1, 10 jun. 2010. Trimestral. Disponível em: <http://politicaexterna.com.br/1163/o-haiti-e-os-desafios-de-uma-reconstrucaosustentavel-um-olhar-sul-americano/>. Acesso em: 7/02/2015.

LINS DA SILVA, Carlos Eduardo. Futebol, paz e riscos para o Brasil no Haiti. Política Externa, São Paulo, v. 13, n. 2, set. 2004. Disponível em: <http://politicaexterna.com.br/1665/futebol-paz-e-riscos-para-o-brasil-haiti/>. Acesso em: $12 / 02 / 2015$.

LOCKE, John. Segundo tratado sobre o governo civil: ensaio sobre a origem, os limites e os fins verdadeiros do governo civil. Petrópolis: Vozes, 2004. Tradução de: Magda Lopes e Marisa Lobo da Costa.

KLEBA, Maria Elisabeth; WENDAUSEN, Agueda. Empoderamento: processo de fortalecimento dos sujeitos nos espaços de participação social e democratização política. Saúde Soc, São Paulo, v.18, n.4, p.733-743, 2009. Disponível em: <http://www.revistas.usp.br/sausoc/article/viewFile/29498/31358>. Acesso em: $12 / 02 / 2015$.

MATIJASCIC, Vanessa Braga. Haiti: uma história de instabilidade política. In: XX ENCONTRO REGIONAL DE HISTÓRIA: HISTÓRIA E LIBERDADE, Franca, 2010. Anais... Franca: ANPHU/SP- UNESP, 2010. 16 p. Disponível em: <http://www.anpuhsp.org.br/sp/downloads/CD XX Encontro/PDF/Autores e Artigos/Vanessa Braga Matijascic.pdf>. Acesso em: 9/02/2015.

MINTZ, Sidney W. Can Haiti Change? Foreign Affairs, v. 74, n. 1, jan. 1995. Bimestral. Disponível em: <http://www.foreignaffairs.com/articles/50576/sidney-wmintz/can-haiti-change>. Acesso em: 5/02/2015.

REZENDE, Lucas Pereira. Uma nova abordagem para o estudo do engajamento do Brasil nas operações de Paz da ONU. Política Externa, v. 21, n. 3, 10 nov. 2012. Trimestral. Disponível em: <http://politicaexterna.com.br/198/abordagem-estudoengajamento-brasil-operacoes-paz-onu/>. Acesso em: 9/02/2015.

ROCHA, Antonio Penalves. Idéias antiescravistas da Ilustração na sociedade escravista brasileira. Rev. bras. Hist., São Paulo, v. 20, n. 39, 2000. Disponível em <http://www.scielo.br/scielo.php?script=sci_arttext\&pid=S010201882000000100003\&lng=pt\&nrm=iso>. Acesso em: 11/02/2015.

SANTOS CRUZ, Carlos Alberto dos. Haiti: Interferências externas e deformações na política interna. Política Externa, v. 19, n. 1, 10 jun. 2010. Trimestral. Disponível em: < 
http://politicaexterna.com.br/1162/haiti-interferencias-externas-e-deformacoes-napolitica-interna/>. Acesso em: 11/02/2015.

SEINTENFUS, Ricardo. INGERÊNCIA OU SOLIDARIEDADE? dilemas da ordem internacional contemporânea. São Paulo em Perspectiva, São Paulo, v. 16, n. 2, p.12-26, 2006. Disponível em: <http://www.scielo.br/pdf/spp/v16n2/12107.pdf>. Acesso em: 19/02/2015.

SEN, Amartya. The Ideia of Justice. Cambridge: Havard University Press, 2009.

THE National Republican Institute for International Affairs. The 1990 Election in Haiti: Report of the international Election Observer Delegation. Washington DC, 1991. Disponível em:

http://www.iri.org/sites/default/files/fields/field_files_attached/resource/haitis_1990 _presidential_parliamentary_and_local_elections.pdf>. Acesso em: 30/05/2015.

VALLER FILHO, Wladimir. O Brasil e a crise haitiana: a cooperação técnica como instrumento de solidariedade e de ação diplomática. Brasília: FUNAG, 2007. 396 p. Disponível em: http://funag.gov.br/loja/download/375-

Brasil_e_a_Crise_Hatiana_0.pdf>. Acesso em: 10/02/2015. 